\title{
Research on the Transformation of Educational Institutions under the Policy of Double Reduction
}

\author{
Yiling Yin ${ }^{1}$, Zhiqing Lai ${ }^{1}$ \\ ${ }^{1}$ Faculty of Foreign Languages, Guangdong Ocean University, Zhanjiang, 524000, CHINA \\ ${ }^{I}$ Faculty of foreign languages, Guangdong Polytechnic College, Zhaoqing, 526000, CHINA \\ *Corresponding author. Email:yinyiling1@stu.gdou.edu.cn ${ }^{1}$,1595695208@qq.com ${ }^{1}$
}

\begin{abstract}
With the development of the education industry, the increasingly fierce educational competition environment has put forward higher requirements for the quality education of primary and secondary school students in China. The introduction of the "double reduction" policy effectively regulates the whole macro society and promotes the transformation of educational institutions. Whether to do a good job in the transformation of primary and secondary education institutions is a major problem facing primary and secondary school students in improving quality education. Thus, this paper will make a case analysis of the policies issued by Beijing Municipal Government and the countermeasures taken by Beijing New Oriental Education and Technology Group. On this basis, the paper discusses the transformation of New Oriental education institutions in the face of the "double reduction" policy from the perspective of parents and students. The research shows that under the "double reduction" policy, the focus of quality education will return to schools. Although the government and educational institutions have taken a series of measures to reduce the "double reduction" policy, the transformation of primary and secondary educational institutions is still restricted by the demands of schools, parents and students. The current transformation of primary and secondary education institutions is not enough to meet the needs of schools, parents and students. To improve the quality education of primary and secondary school students not only needs to perfect the transformation of educational institutions, but also needs to adjust the school examination system or teaching system. This paper will examine this through qualitative analysis and a case study of New Oriental Education \& Technology Group to conclude.
\end{abstract}

Keywords: Quality-oriented education, Double reduction policy, Education transformation, Primary and middle school students

\section{INTRODUCTION}

Chinese education is now like a large rat race, with a lot of over-step learning and pre-emptive education increasing the extra-curricular pressure on primary and secondary school students day by day. According to the report, in China, $47.3 \%$ of middle school students attending After-school tutoring(AST) classes[1], meaning that AST classes seem to have become another necessary school for students, regardless of whether they excel or not. Thus, at the annual plenary sessions in March 2021, "double reduction" work was mentioned for the first time, and on 24 July 2021, the "double reduction" policy was officially issued and implemented, and several pilot cities were set up across the country. The two reductions in this policy are a reduction in the burden of homework on students and a reduction in the burden caused by AST classes. Since then, the reform of primary and secondary education can be officially kicked off. Under the "double reduction" policy, many provinces and cities have made it clear that AST classes are no longer allowed to provide any extra-curricular training to students. This regulation has taken many educational institutions by surprise, with the education stock market plummeting and mass layoffs in many education positions. Whether it can meet the multi-faceted needs of institutions, schools and students and do a good job of transforming primary and secondary education is a question we should discuss. This article will start from New Oriental Education Technology Group's response to the "double drop" policy transformation-the establishment of a quality education center-and analyze the deeper purpose of the "double drop" policy. In addition, the author will 
analyze whether New Oriental Education Technology Group will carry out corporate transformation in response to the "double drop" policy. Whether the transformation of New Oriental can meet the requirements of government policy. The analysis also looks at whether New Oriental's transformation has achieved the desired effect of the "double reduction" policy.

\section{THE BASIC CONNOTATION AND FUNCTION OF THE "DOUBLE REDUCTION"'POLICY}

As the burden of primary and middle school students is too heavy, short-term, utilitarian problems have not been fundamentally solved, the "double reduction" policy came into being. The "double reduction" policy means reducing the burden of homework and after-school training for students in compulsory education. It is obvious that its implementation mainly targets the two aspects of extracurricular institutions and school management. On the one hand, it effectively standardizes the number of off-campus training institutions and restrains the development of capital randomization. On the other hand, it shortens the time for primary and secondary school students to train outside the school and shifts the focus of education from remedial classes to schools. In addition, in terms of in-school education management, It aims at ensuring the quality of classroom education, improving the level of teaching management and perfecting after-class service system.

It is easy to see how the "double reduction" policy has helped improve the quality of education for students. It has narrowed the gap between rural and urban schools and ensured equal access to education for students. At the same time, the "double reduction" policy also plays an important role in promoting the individualized development of students and alleviating social anxiety.

\section{CASE STUDY-RESPONSES TO THE BEIJING NEW ORIENTAL QUALITY GROWTH CENTRE AS AN EXAMPLE ANALYSIS}

\subsection{Policies Issued by the Beijing Government Specifically for Educational Institutions}

On the day the "double reduction" policy was issued, nine cities were set up across the country as the pilot cities. In the following, authors will focus on what exactly policies have been issued by the governments of Beijing and how educational institutions-- New Oriental Education \& Technology Group in Beijing have responded to these politics.
The Beijing government has held a meeting to explicitly ban AST classes for primary and junior high school students this summer. This means that courses such as math and English, which are taught in schools, are not allowed to be offered. Plus, all educational institutions are required to stop advertising and there will be no approval for setting up new institutions. As for schools and teachers, the government requires that both improvement and management. That is to say, the quality of teachers' teaching and after-school homework tutoring need to be improved, and the behaviour of school teachers giving extra lessons to students outside the school be rigorous prohibited.

\subsection{The Response of the New Oriental Education \& Technology Group to the Implementation of the "Double Reduction" Policy}

New Oriental Education \& Technology Group, one of the largest AST education companies in China and is also one of the listed educational institutions, is bound to be hit very hard after the official release of the "double reduction" policy. Within only half a month of the issuance of the "double reduction" policy, Beijing New Oriental established the Quality Education Growth Centre, with the aim of transforming its original test-based education, which cultivates subjects such as Chinese, mathematics and English, into quality education, which cultivates children's multiple abilities. This growth centre contains six sections, the Academy of Chinese Studies and Reading, the Language and Business Literacy Academy, the Arts and Creativity Academy, the Nature Science and Creativity Space Academy, the Intellectual and Physical Sports Training centre and the Quality Parenting studying centre.[2] Turning the training of students into the training of parents, turning the tutoring in professional subjects into the cultivation of interests such as arts, sports and something that won't be tested in schools' exam. The Beijing government launched a policy and New Oriental immediately came out with a response. It seems to be a transformation made in response to the government's quality education reform, like the curriculum launched by New Oriental and all educational institutions in the market are so reformed, this "double reduction" policy seems can't really achieve the desired effect.

In order to discuss this issue in more detailed, the authors will then analyse whether the changes made by New Oriental in response to the "double reduction" policy are suits to the educational reforms that the government wants, from the perspective of parents and students. 


\subsection{The Impact of the "Double Reduction" Policy on New Oriental Students}

At the student level, we have mentioned that New Oriental has created the Quality Education Centre to provide students with a different curriculum from that offered at school, (i.e. a test-based curriculum, with quality development classes that allow students to exercise their minds) improve their artistic skills and develop some logical thinking skills. This is a good move on an educational level, as the institution is no longer focused on the children's grades, but on the abilities of each child. But here's the problem. Educational institutions are the first moving towards a transition from exam-based education to quality education, but schools are not. The Academic Test for the Junior High School Students and the independent recruitment of each key high schools, are all based on exam results from exam-based education. Some of the concepts and assessments in our educational systems are still not fully aligned with the requirements of quality education. For instance, most basic education still focuses on the promotion and selection of subjects, and the examination scores are still the sole indicator of students' merit. [3] This is where the school curriculum deviates from what this "double reduction" policy reform is trying to achieve, the effect of reducing the burden and the ultimate goal of quality education that our country has always wanted to achieve.

Most of the students who attend after-school tutorial classes are those who really cannot learn in the school classroom, they may not be able to remember the knowledge points taught by the teacher once. Also, the teacher doesn't have the energy to take care of every student in the class, and can only follow the learning progress of most students. These children will need after-school tutorials to help them further grasp what they did not understand in the classroom. The second type is that the knowledge in the school classroom is no longer sufficient for them, these children are very good learners but also need to go to extra-curricular classes in order to learn more than other students and master more knowledge so that they can cope with the independent entrance examinations of some famous high schools, these examinations are often more difficult than the secondary school examinations, the purpose is to select particularly outstanding students to enter the school, and the questions in the secondary school examinations may not be able to The purpose of these exams is to select the best students for admission to schools, and the questions on the Chinese exams may not be graded for top students. When extra-curricular classes are banned, the first concern is that the access of their knowledge of both groups of students, those who cannot get the knowledge they need from classroom learning. Given that other educational institutions have not given any reform measures other than bankruptcy and layoffs, we will only discuss this from the New Oriental Education, which has already started to institutionalise education reform. It therefore becomes urgent to address the needs of these two groups of students to gain knowledge. The Ministry of Education is currently proposing to extend the working hours of school teachers to meet the needs of students for extra-curricular tutoring, but this is not only a burden on schools and teachers, but it also seems to be impossible to meet the needs of a second group of students who want to acquire a wider range of knowledge which seems still falls short of the "double reduction" policy's goal of reducing the burden on students.

\subsection{The Impact of the "Double Reduction" Policy on the Parents of New Oriental Students}

The transformation of educational institutions has affected many families in China, not only for their children but also for their parents. The establishment of Beijing New Oriental Quality Education Growth Center, which will offer several home education methods, time allocation methods, effective learning skills and many other courses for parents. This can help parents become better so as to better teach their children. However, it can be found that the burden of parents is still there. Parents' educational expenditure burden and psychological burden have not been effectively alleviated. The "double reduction" policy returns the focus of education to schools.

Improving the quality education of middle school students is the goal of the transformation of educational institutions, and the scarcity of high-quality resources makes the capital see the opportunity, so one-to-one education prevails. When it comes to private education, not every family can afford it. Although new Oriental's parent training program is free of charge, many parents doubt whether their abilities are as good as those of professional teachers after the classes.

Education also has the function of social stratification and intergenerational transmission. After-school training will make it easier for the families with higher economic and social status to obtain a favorable position for their children's future development by paying extra education expenses, will lead to the solidification of social class and the intergenerational transmission of economic and social status[5].

This actually increases the pressure on parents to pay for education. The reason is that most parents hope their children will not lose in learning, and they are not professional enough in education, which to some extent promotes the wave of signing up for extracurricular classes. This widening gap between the rich and the poor will also make some parents anxious psychological burden, which is a challenge to the development of 
family education. As a result, the burden on parents is even heavier. Besides, Most of the reasons for the existence of remedial classes are that they can provide high-quality educational resources and relieve the pressure of parents to help their children. Nowadays, the focus of quality education has shifted from remedial classes to schools. In the face of the uneven quality of school education, quality education resources appear extremely precious. The scarcity of quality education resources forces parents to realize the importance of family education. However, parents don't seem to have the energy to devote to tutoring their children. The model for parents to attend classes may seem novel, but most parents don't have the time or energy. They are already very tired with their own work and have to attend training classes for extra time. When they get home, they also take time to digest the way of thinking taught in class and pass it on to their children. In fact, the purpose of parent training classes is not necessary to cultivate excellent parents, but to create a family learning atmosphere, so as to reflect the importance of family education. Since ancient times, China has attached great importance to family education, and this kind of education should be spontaneous rather than deliberate. As a result, such a transformational program, while ostensibly helping parents to participate in their children's development and learning, is not. It defeats the desired effect of the "double reduction policy" and not only does not reduce the mental pressure on children for extra-curricular training, but also increases the financial pressure within the family.

\section{DISCUSSION}

The starting point of the "double reduction" policy is clear to all of us. The purpose of reducing the burden on students and parents is to shift the focus of education, hoping that the essence of education will return to schools, and that the essence of teaching in schools will fall on quality education. The establishment of the Beijing New Oriental Quality Centre can be said to be based on a complete understanding of the deeper purpose of the government's policy. On a corporate level, economically this is a good direction for transformation, but standing in the context of education in the country as a whole, it is perhaps not a good decision. Explained in terms of the nudge factor, schooling will drive educational institutions to offer school-based programmes, and the shift in quality education in educational institutions will inevitably drive changes in some schools in terms of promotion examinations. Take the programming course launched by New Oriental as an example:

The domestic children's programming education market is still in its infancy, but with national policy guidance and a large injection of capital, it has huge potential for development, and it is expected that within the next ten years most provinces and cities in China will probably incorporate programming into the education of basic subjects and conduct relevant audit examinations[4].

According to a study by Xue, the increase in the high school admission rate has promoted students' participation in extracurricular tutoring. This study revealed that parents with higher social strata usually try to get their kids involved in tutoring in order to improve their chances of entering the demonstration high school. Only the increase in the demonstration high school acceptance rate can effectively reduce the participation rate of extracurricular tutoring.[6] This article is not intended to accuse the "double reduction" policy of inadequacies, only this policy if it wants to achieve its ultimate desire to transform the Chinese education into quality education, the government cannot just a single suppression of out-of-school training institutions, but also to the examination system or teaching system to make some adjustments, for a large number of education market suddenly vacant, but also to guide, after all, so many numbers of out-of-school training institutions also can not disappear overnight or suddenly find a way to transform their companies themselves.

\section{CONCLUSION}

In a word, the development of education adapts to the trend of the times. Under the guidance of the national "double reduction" policy, it is imperative to reform teaching institutions in the face of the demand of improving the quality education of primary and secondary school students. It also means that the focus of quality education will return to schools. Therefore, the reform measures of educational institution transformation are all around the change of the government's demand for improving the quality of primary and secondary school students. According to the literature analysis of this case, it can be seen that although the transformation of primary and secondary education institutions has promoted the standardized development of the education industry and tried to balance the demands of schools, parents and students, it still fails to meet their expectations under the double-reduction policy mode. In practical teaching, educational institutions not only pay attention to the grades of primary and secondary school students but also pay more attention to the ability of each student. They gradually shift from exam-oriented education to quality-oriented education. Thus, increasing the learning burden of primary and secondary school students. On the other hand, the educational expenditure of the family and the psychological burden of parents have not been effectively alleviated. This is also a major obstacle to educational transformation. Nowadays, the "double reduction" policy affects many educational institutions like New Oriental. In order to improve the quality 
education of primary and secondary school students, China should not only limit the off-campus training institutions but also perfect the examination system in school and improve the teaching level. In addition, they should also actively guide the transformation of educational institutions and promote the balanced development of educational resources. These practices are conducive to reduce a large number of pre-emptive education and over-step learning, slow down the burden of primary and secondary school students, short-term and utilitarian problems, so as to promote the successful transformation of educational institutions, improve the quality education of primary and secondary school students.

As the double reduction policy has only been in place for two months at the time of writing, there are limitations in terms of material collection and analysis. The shortcomings of the feedback from the provinces and municipalities, as well as the fact that the New Oriental Education \& Technology Group is always working on improvements, leave room for further exploration of this article. The authors believe that the increased feedback on the double reduction policy will be very useful for the authors to continue their in-depth research.

\section{ACKNOWLEDGMENT}

In the process of writing the dissertation, from the selection of the topic to the identification of ideas, from the collection of information, the formulation of the outline to the writing and revision of the content, and then the sorting out of many ideas, we have to thank our dissertation teacher, Mrs. Zou, for his careful guidance and artful guidance. We would like to express our most sincere gratitude and respect to Mrs. Zou.

We would also like to express our gratitude to all the professors who have taught us and helped us during this period of time, including Professor Meer and Professor Gearon. I would like to thank them all for their guidance, patience and selfless assistance.

Thank you to our beloved alma mater for the privilege of this opportunity, thanks to Guangdong Ocean University and Guangdong Institute of Technology.

Thank you to our classmates and friends for your encouragement, care and selfless help during the writing of our thesis.

Finally, a heartfelt thank you to our families for your continuous support and encouragement.

\section{REFERENCES}

[1]Xue, H. (2016). Extracurricular tuition, academic performance, and social reproduction. Education and Economy, 32(2),p32-43.
[2]Beijing New Oriental Quality Education Growth Centre, (2018), Cultivating well-rounded quality talents, Beijing New Oriental Quality Growth Centre is upgraded and launched, [online], [Accessed 2 September 2021], Available from: https://mp.weixin.qq.com/s/JmgI61-Zsykcd47TgtuqQ.

[3]Yang Zhaoshan, Shi Yizhi, (2018), Policy Evolution and Theoretical Exploration of Well-Rounded Education, Educational Research, 39(12), p18-28+80.

[4]Zhang Mian, (2020), The Present Situation of Children's Programming Education and Its Countermeasures, Computer Knowledge and Technology, 16(23), p105-108.

[5]Dai Ruihua, Yang Bingcan, (2017), Governance of Out-of-school Training Institutions Abroad: Current Situations, Experiences, Problems and Enlightenments, Teacher Education Research, 29(05), p101-108.

[6]Xue, H., \& Fang, C. (2021). The impact of high school entrance examination competition on students' participation in extracurricular tutoring in the compulsory education period: An empirical analysis based on the data of China Family Panel Studies. Best Evidence in Chinese Education, 8(2):1081-1102. 